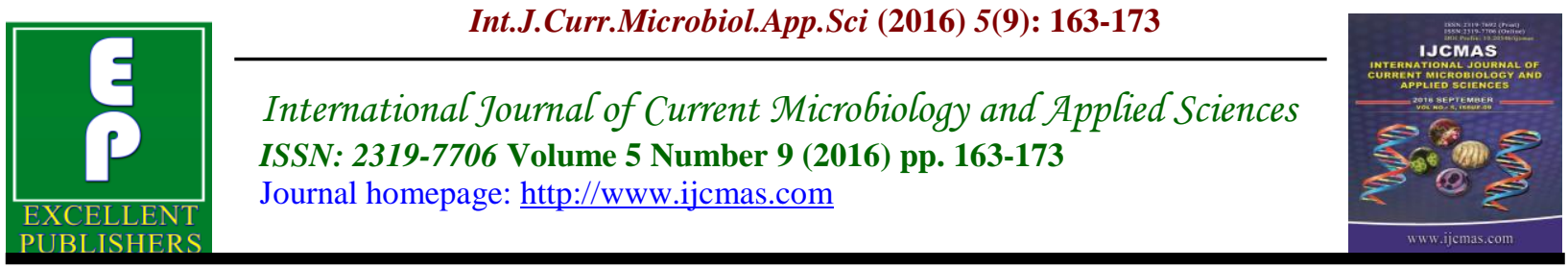

Original Research Article

http://dx.doi.org/10.20546/ijcmas.2016.509.018

\title{
Preliminary Screening and Phytochemical Profile of Mangifera indica Leave's Extracts, Cultivated in Iraq
}

\author{
Dhuha Alshammaa* \\ Department of Pharmacognosy, College of Pharmacy, University of Baghdad, Baghdad, Iraq \\ *Corresponding author
}

\begin{abstract}
A B S T R A C T
Keywords

Phytochemical screening, Secondary metabolites, Mangifera indica, Anacardiaceae, Preparative high performance liquid chromatography, etc.

\section{Article Info}

Accepted:

13 August 2016

Available Online:

10 September 2016

The main objective of this study was to evaluate the Mango leaves that recently cultivated in Iraq, depends on preliminary investigation and phytochemical profiles of Mangifera indica leaves (F.Anacardiaceae) extracted with different polar solvents. Then we chose ethyl acetate, the most appropriate solvent to obtain maximum amount of phenolic compounds from mango leaves so that it can be used as nutritional supplement. The preliminary phytochemical screening was performed by the standard methods as described by Harborne. These tests indicate the presence of alkaloids, Tannins, flavonoids, steroids and absence of saponin glycosides. In addition Four different leaf extracts (methanol, ethanol, nbutanol and ethyl acetate) were analyzyed by Preperative high performance liquid chromatography (PHPLC) to identify bioactive compounds. The results confirmed that Mangifera indica leaves accumulate large number of secondary metabolites in different percentages, but the higher percentage related to flavonoid glycosides. So that we analyzed the ethyl acetate extract of fresh mango leaves by GC-MS and the result show high percentage of quercetin. These findings will be helpful to the phytochemists and pharmacologists for identification of new active principles in future.
\end{abstract}

\section{Introduction}

Traditionally used medicinal plants have recently attracted the attention of the biological scientific communities. This has involved the isolation and identification of secondary metabolites produced by plants and their use as active principles in medicinal preparations.

Plants have limitless ability to synthesize aromatic secondary metabolites, most of which are phenols or their oxygensubstituted derivatives (Rajendra Prasad et al., 2013).

Extraction involves separation of medicinally active constituents in plant tissue from inactive/inert components by using selective solvents and the most appropriate extraction technologies. Solvents diffuse into the solid plant tissues 
and solubilize compounds of similar polarity (JoonaK, Sowmia et al., 2013). Our plant is Mangifera indica Linn., it is a large evergreen tree, belongs to the family Anacardiaccae. It is commonly known as 'Maram' in Tamil, 'Mango' in English, 'Aam' in Hindi and 'Aamra' in Sanskrit. Different varieties of mango have been cultivated throughout the world and recently cultivated in Iraq (Rajan et al., 2011). It consists of about sixty genera and six hundred species, which are mainly tropical trees and shrubs. Its parts are commonly used in folk medicine for a wide variety of remedies. Many phenolic compounds have been detected in Mango peels, bark, Pulps and seed kernels. Several pharmacological activities of mango extracts have been reported including anti-inflammatory, antioxidant, anti-allergic, anthelmintic and antiamoebic. Herbal drinks are very popular, as they contain natural constituents especially phenolic compounds (Abdelnaser Abdelghany et al., 2010).

The mango is a rich source of various polyphenolic compounds. The major polyphenols in the mangoare: mangiferin, catechins, rutin, quercetin, kaempferol, rhamnetin, anthocyanins, gallic and ellagic acids, propyl and methyl gallate, benzoic acid, and protocatechuic acid. The amounts of the different polyphenolic compounds in the mango vary from part to part (pulp, peel, seed, bark, leaf, and flower) (Talba et al., 2014). Polyphenols are secondary metabolites of plants and are widely distributed in beverages and plant-derived foods. Human consumption studies indicate $1 \mathrm{~g}$ of total polyphenols is frequently consumed per day and it is not anticipated that any acute or lethal toxicity would be observed through the oral intake route (Augustin Scalbert et al., 2000). Phenolic compounds have the capacities to quench lipid peroxidation, prevent DNA oxidative damage, scavenge free radicals and prevent inhibition of cell communication, all of which are precursors to degenerative diseases.

Free radicals cause depletion of the immune system antioxidants, change in gene expression, and induce abnormal proteins resulting in degenerative diseases and aging. Use of pure isolated compounds has been found to be less effective than the use of crude mixtures from the particular mango part suggesting that synergism of the various mango polyphenols is important for maximum antioxidative activity (Martin Masibo et al., 2008).

\section{Materials and Methods}

\section{Identification of mango leaves}

The mango species used in this study were identified by their leaves by the taxonomist Dr. Alialmosawi.

\section{Collection of the mango leaves}

Mangifera indica leaves were collected from mango trees in the garden. The leaves were washed by tap water and dried at room temperature, then made as powder using mortar and pestle. The powder was preserved in an airtight container and kept in a cool dry place.

\section{Preparation of methanol extract of mango leaves}

$50 \mathrm{~g}$ of the powdered leaves was extracted exhaustively over a period of 10 hours using continuous hot extraction method with $350 \mathrm{ml}$ of methanol in a soxhlet apparatus. The extract was concentrated to a solid form using rotary evaporator at $40^{\circ} \mathrm{C}$.

\section{Preparation of ethanol extract of mango leaves}

$50 \mathrm{~g}$ of the powdered leaves was extracted 
with $200 \mathrm{ml}$ of ethanol by maceration over night at room temperature. The extract was filtered then concentrated and divided into small portions, one for identification and the other part was partioning with n-butanol and ethyl acetate respectively, then each fraction was concentrated to small volume for further study.

Preparation of ethyl acetate extract of mango leaves

$50 \mathrm{~g}$ of fresh mango leaves was extracted with ethyl acetate by maceration at room temperature over night using magnetic stirrer, then filtered and concentrated by rotary evaporator to small volume for further study.

\section{Phytochemical tests}

$10 \mathrm{~g}$ of dried mango leaves powder was extracted by boiling with water for $15 \mathrm{~min}$.Filtered and was evaluated for the presence of phytochemical compounds using standard methods (Harborn, 1998).

\section{Detection of Steroids by Lieberman- Burchard test}

Take $1 \mathrm{ml}$ of the aqueous extract in a test tube then add $5 \mathrm{ml}$ of anhydrous acetic acid and shake well. Take 4 drops of the above mixture and place in a porcelain dish, and then add one drop of conc. $\mathrm{H}_{2} \mathrm{SO}_{4}$.A change of color from rose, through red, violet and blue to green.

The colors are slightly different from compound to compound.

\section{Detection of Cardiac Glycosides (Keller- Killians Test)}

To $1 \mathrm{ml}$ of aqueous extract add $1 \mathrm{ml}$ of glacial acetic acid containing one drop of ferric chloride solution. Then add $1 \mathrm{ml}$ of concentrated sulphoric acid to the above mixture in drops to make two layers. A brown ring obtained at the interface indicated the presence of ade-oxy sugar characteristic of cardenolides.

\section{Detection of Saponins (Froth Test)}

$1 \mathrm{ml}$ of aqueous extract diluted with distilled water to $20 \mathrm{ml}$ which was shaken in a graduated cylinder for 15 Seconds. Formation of foam layer after 15 minutes indicated the presence of saponins.

\section{Detection of Tannins}

To $1 \mathrm{ml}$ of aqueous extract add few drops of alcoholic solution of $0.1 \% \mathrm{Fecl}_{3}$ dark blue, greenish black soluble compounds indicate the presence of tannins (Aiyegoro et al., 2010).

\section{Detection of Flavonoids}

$2 \mathrm{ml}$ of aqueous extract added few drops of $10 \%$ sodium hydroxide solution. This produces a yellow coloration. A change in color from yellow to colorless on addition of dilute hydrochloric acid is an indication for the presence of flavonoids (Syamsudin Abdillah et al., 2015).

\section{Detection of Alkaloids}

Add few drops of mayer's reagent to $1 \mathrm{ml}$ of the queous extract. White precipitate indicate the presence of alkaloids. Also few drops of dragendorf's reagent give orange precipitate with alkaloids (Javier et al., 2014).

\section{Preparative High performance liquid chromatography (PHPLC)}

Fractionation of the Mangifera indica extract was performed by PHPLC to identify active compounds. An isocratic HPLC, 
variable wavelength UV-Visible Detector, and reverse phase $\mathrm{C} 18$, Phenomenex column $(250 \mathrm{X} 4.60 \mathrm{~mm})$ was used. The mobile phase components acetonitrile: water: aceticacid (60:40:0.5) were filtered through 0.2 micron membrane filter before use, and pumped from the solvent reservoir at a flow rate of $10 \mathrm{ml} / \mathrm{min}$, which yielded column backup, max.pressure 25pk. The column was maintained at room temperature. $2 \mathrm{ml}$ of different Mango leaves extracts were injected (Javier et al., 2014).

\section{Results and Discussion}

\section{Phytochemical analysis}

The results of qualitative phytochemical analysis of the crude extract of $M$. indica leaves are shown in Table 1.

\section{Preparative High performance liquid chromatography (PHPLC)}

The following chromatograms confirmed the presence of some phenolic compounds in all Mango leaves extracts.

Preliminary phytochemical investigation confirmed that mango leaves are rich with several chemical constituents as shown in table (1) by using specific tests for each group of compounds. Mango leaves are good source for Alkaloids, Flavonoids, Tannins, Steroids and Cardiac glycosides while saponin glycosides are absent.

Table.1 Qualitative phytochemical analysis of $M$. indica leaves

\begin{tabular}{|c|c||c|}
\hline Phytochemicals & Test & Crude extract \\
\hline \hline Alkaloids & $\begin{array}{c}\text { Dragendroff's test } \\
\text { Mayer's test } \\
\text { Flavonoids }\end{array}$ & Alkaline reagent \\
Tannins & FeCl3 test & + \\
Steroids & Liebermann-Burchard test & + \\
Saponins & Frothing test & - \\
Cardiac glycosides & Keller- Killians Test & + \\
\hline
\end{tabular}

Fig.1 Mango tree

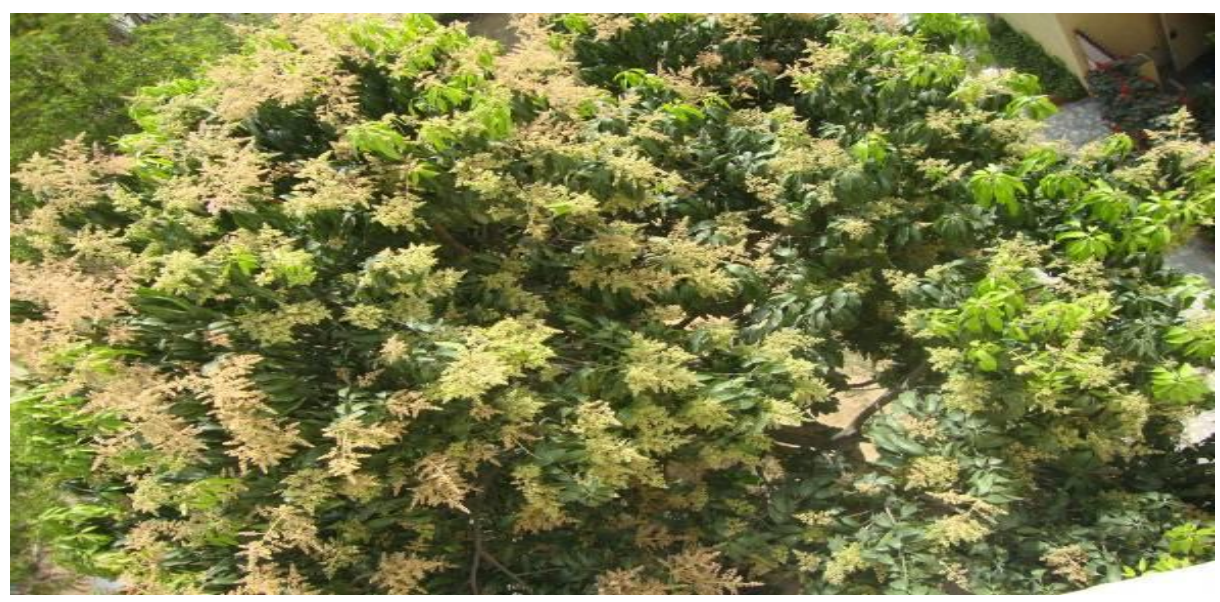


Fig.2 Methanolic Mango leaf extract

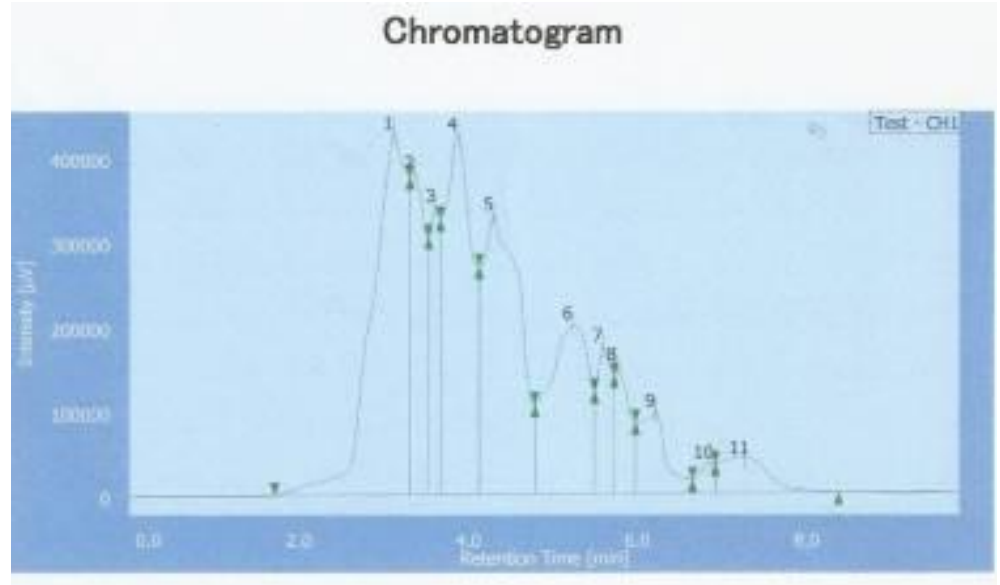

\begin{tabular}{|c|c|c|c|c|c|}
\hline $\mathrm{CH}$ & $t R$ [min] & Area $[\mu \mathrm{V} \cdot \mathrm{sec}]$ & Height $[\mu \mathrm{V}]$ & AreaK & Heights \\
\hline 1 & 3.117 & 12351524 & 430644 & 22.744 & 16.489 \\
\hline 1 & 3.367 & 4571572 & 381079 & 8.418 & 14.591 \\
\hline 1 & 3.617 & 2772721 & 341060 & 5.106 & 13.059 \\
\hline 1 & 3.875 & 9602864 & 424866 & 17.683 & 16.268 \\
\hline 1 & 4.300 & 10038327 & 330871 & 18.485 & 12.669 \\
\hline 1 & 5.233 & 6716438 & 200990 & 12.368 & 7.696 \\
\hline 1 & 5.592 & 2126882 & 174863 & 3.916 & 6.695 \\
\hline 1 & 5.758 & 1800219 & 152949 & 3.315 & 5.856 \\
\hline 1 & 6.208 & 2206906 & 96984 & 4.064 & 3.713 \\
\hline 1 & 6.842 & 452299 & 36137 & 0.833 & 1.384 \\
\hline 1 & 7.267 & 1666183 & 41262 & 3.068 & 1.580 \\
\hline
\end{tabular}

Fig.3 Ethanolic Mango leaf extract

Chromatogram

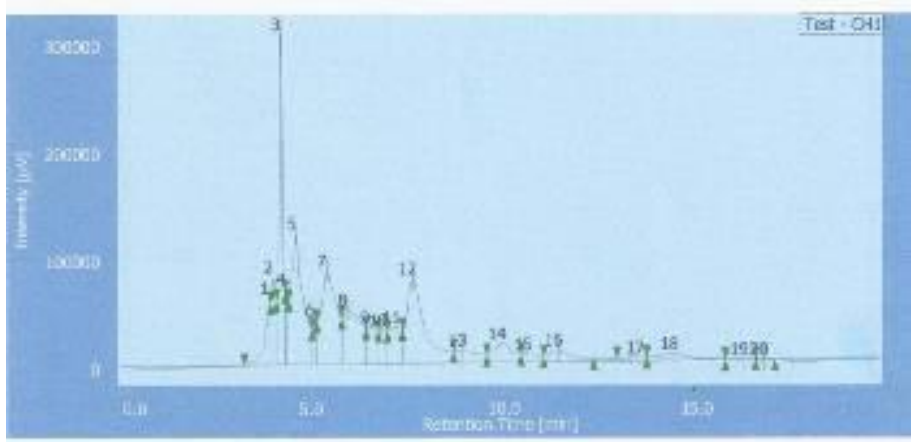


Int.J.Curr.Microbiol.App.Sci (2016) 5(9): 163-173

\begin{tabular}{|c|c|c|c|c|c|}
\hline $\mathrm{CH}$ & UR [min] & Arwa [uiV-sec] & Height $[\mu \vee]$ & Areak & Heicht? \\
\hline 1 & 3.917 & 609123 & 62362 & 3.569 & 5.057 \\
\hline 1 & 4.033 & 625251 & 81171 & 3.663 & 7.624 \\
\hline 1 & 4.217 & 1084001 & 310493 & 11.038 & 29.161 \\
\hline 1 & 4.35B & 397023 & 70596 & 2.376 & 6.6.31 \\
\hline 1 & 4625 & $24 \mathrm{Bb} 233$ & 122323 & 14.561 & 11.488 \\
\hline$I$ & 5.100 & 290342 & 41304 & 1.701 & 3.879 \\
\hline 1 & 5.408 & 2388824 & 87083 & 13.986 & 8.179 \\
\hline 1 & 5.950 & 1639033 & $505 B 4$ & 9.003 & 4.748 \\
\hline 1 & 6.525 & 602642 & $3 \times 819$ & 3.531 & 3.176 \\
\hline 1 & 6.850 & 461902 & 31174 & 2,706 & 2.928 \\
\hline 1 & 7.206 & 745101 & 3386! & 4.366 & 3.181 \\
\hline 1 & 7.633 & 2573025 & 79006 & 15.075 & 7.420 \\
\hline 1 & 8.925 & 500445 & 12029 & 2.932 & 1.130 \\
\hline 1 & 9.950 & 813966 & 17892 & 3.597 & 1,680 \\
\hline 1 & 10.625 & 233317 & 7740 & 1.367 & 0.727 \\
\hline 1 & 11.408 & 157042 & 11193 & 2.678 & 1.052 \\
\hline 1 & 13.525 & 129649 & 3402 & 0.760 & 0.320 \\
\hline 1 & 14.417 & 367696 & 6517 & 2.154 & 0,612 \\
\hline 1 & 16,225 & 41413 & 1198 & 0.243 & 0.113 \\
\hline 1 & 16.733 & 22844 & 1011 & 0.134 & 0.095 \\
\hline
\end{tabular}

Fig.4 n-butanol Mango leaf extract

\section{Chromatogram}

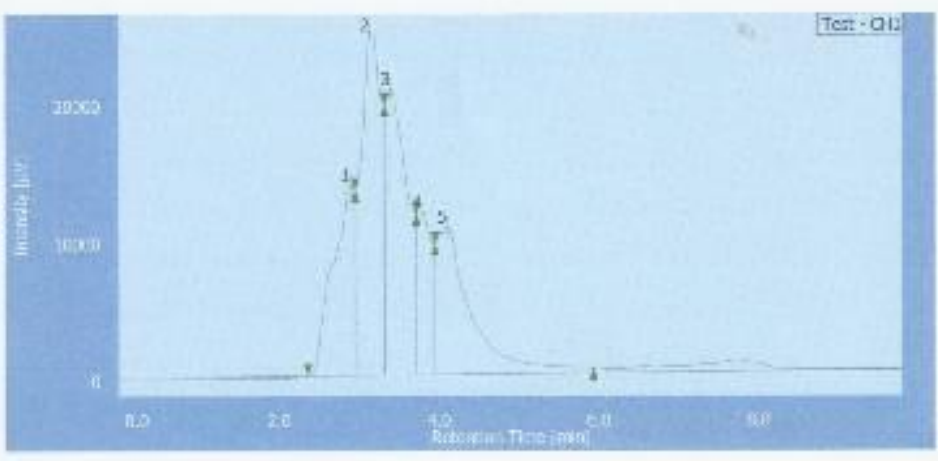

\begin{tabular}{|c|r|r|r|r|r|}
\hline $\mathrm{CH}$ & $\mathrm{tR}[\mathrm{min}]$ & Area $[\mu \mathrm{V}-\mathrm{sec}]$ & Height $[\mu \mathrm{V}]$ & Area\% & Heights \\
\hline 1 & 2.892 & 255709 & 13796 & 16.216 & 16.816 \\
\hline 1 & 3.142 & 443263 & 24917 & 28.111 & 30.373 \\
\hline 1 & 3.400 & 398297 & 20781 & 25.259 & 25.332 \\
\hline 1 & 3.800 & 152203 & 11804 & 9.652 & 14.389 \\
\hline 1 & 4.100 & 327373 & 10739 & 20.761 & 13.091 \\
\hline
\end{tabular}


Fig.5 Ethyl acetate Mango leaf extract

\section{Chromatogram}

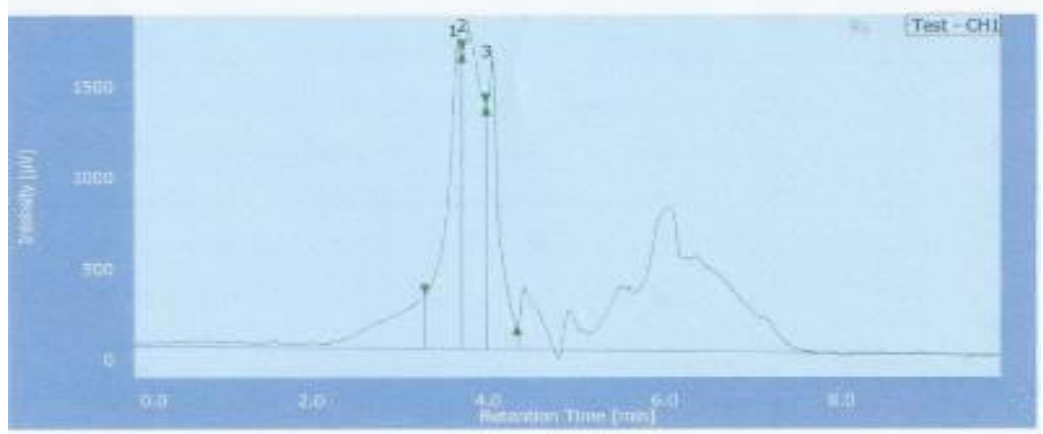

\begin{tabular}{|c|r|r|r|r|r|}
\hline $\mathrm{CH}$ & tR [min] & Area [uV-sec] & Height [uV] & Arsa\% & Height\% \\
\hline 1 & 3.667 & 20260 & 1692 & 32.817 & 33.728 \\
\hline 1 & 3.775 & 25984 & 1741 & 42.088 & 34.696 \\
\hline 1 & 4.050 & 15492 & 1584 & 25.094 & 31.576 \\
\hline
\end{tabular}

Fig.6 Std.Caffeic acid

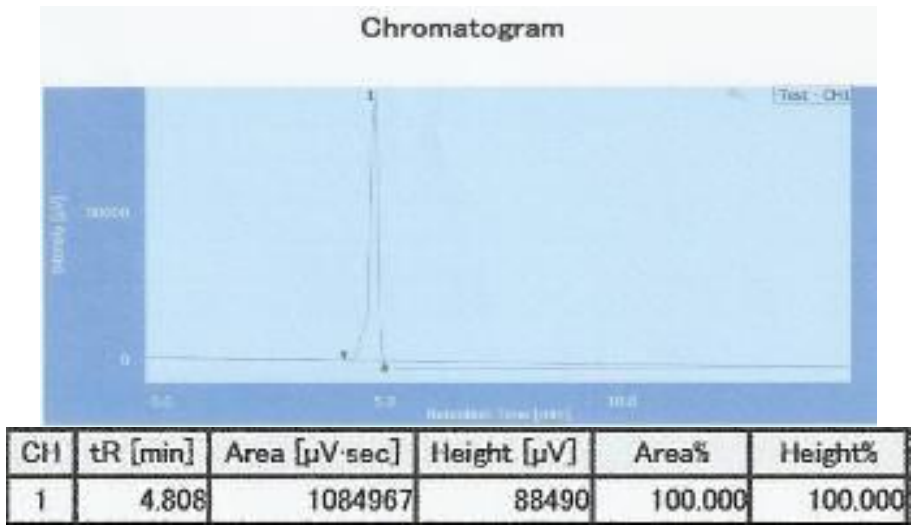

Fig.7 Std.Chlorogenic acid

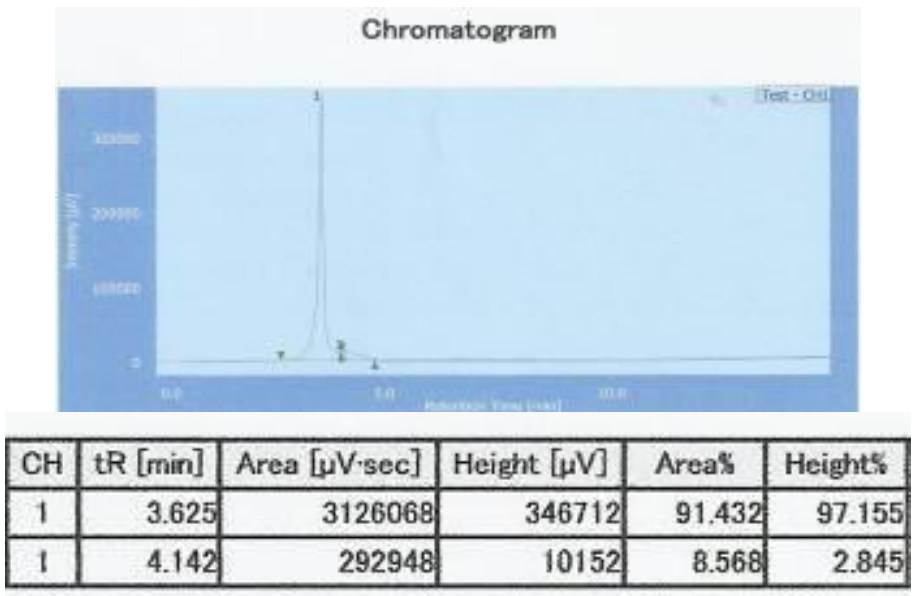


Fig.8 Std.Rutin

Chromatogram

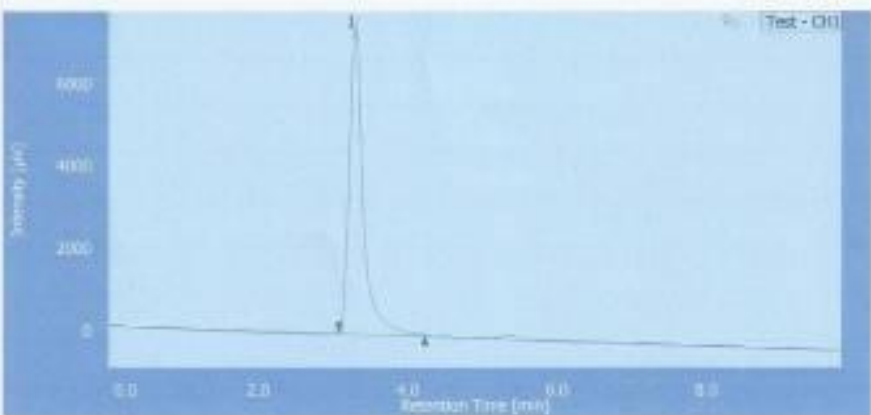

\begin{tabular}{|c|c|c|c|c|c|}
\hline $\mathrm{CH}$ & $t R$ [min] & Area [ $\mu \mathrm{V}$-sec] & Height [uV] & Area\% & Height \\
\hline 1 & 3.300 & 97201 & 7450 & 100.000 & 100.0 \\
\hline
\end{tabular}

Fig.9 Std.Quercetin

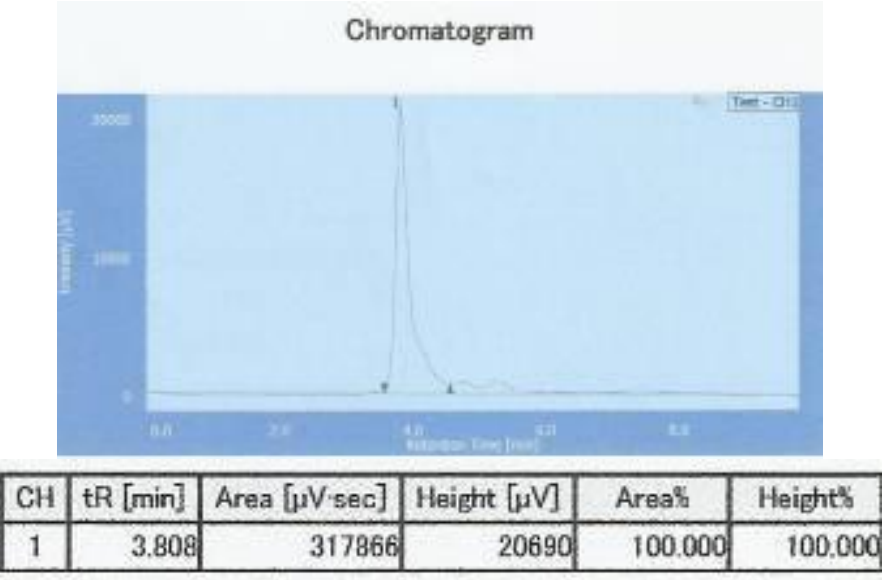

Fig.10 Std.Kambferol

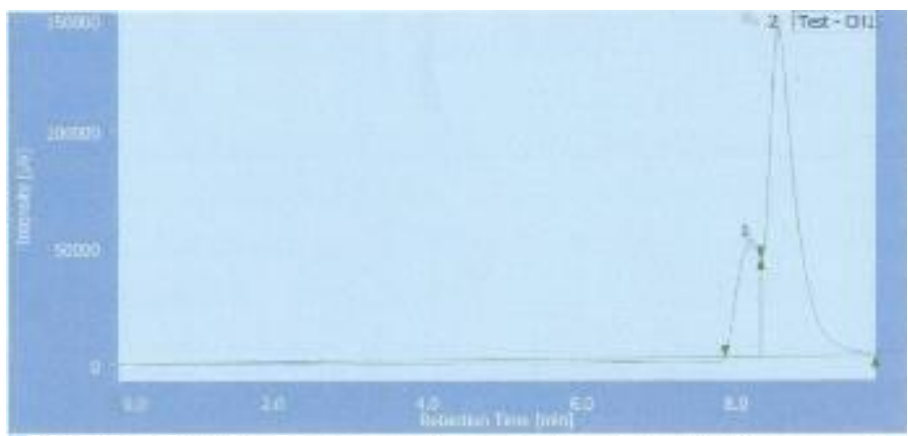

\begin{tabular}{|c|c|c|c|c|c|}
\hline $\mathrm{CH}$ & tR [min] & Area $[\mu V \cdot \mathrm{sec}]$ & Height [uV] & Area\% & Heights\% \\
\hline 1 & 8.175 & 953872 & 50037 & 21.653 & 26.260 \\
\hline 1 & 8.542 & 3451454 & 140510 & 78.347 & 73.740 \\
\hline
\end{tabular}


Fig.11 GC-MS chromatogram of ethyl acetate extract of mango leaves

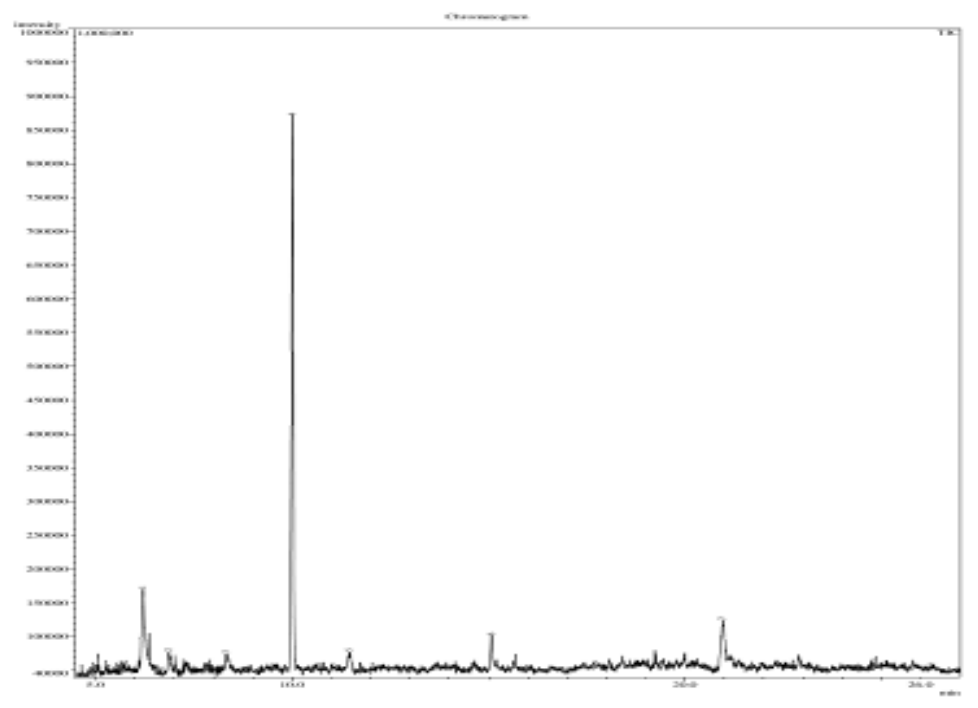

Fig.12 GC-MS chromatogram of phenolic standards

\begin{tabular}{|l|l|l|l|l|l|}
\hline Peak R.Time & Area & Area\% & Height & Height\% \\
\hline 1 & 6.21 & 652668 & 15.60 & 113011 & 10.00 \\
\hline 2 & 6.86 & 161600 & 3.86 & 32012 & 2.83 \\
\hline 3 & 8.33 & 78782 & 1.88 & 19910 & 1.76 \\
\hline 4 & 10.01 & 2524326 & 60.33 & 821984 & 72.77 \\
\hline 5 & 11.46 & 145204 & 3.47 & 26641 & 2.36 \\
\hline 6 & 15.07 & 177047 & 4.23 & 47801 & 4.23 \\
\hline 7 & 20.96 & 444644 & 10.63 & 68246 & 6.04 \\
\hline & & 4184271 & 100.00 & 1129605 & 100.00 \\
\hline
\end{tabular}

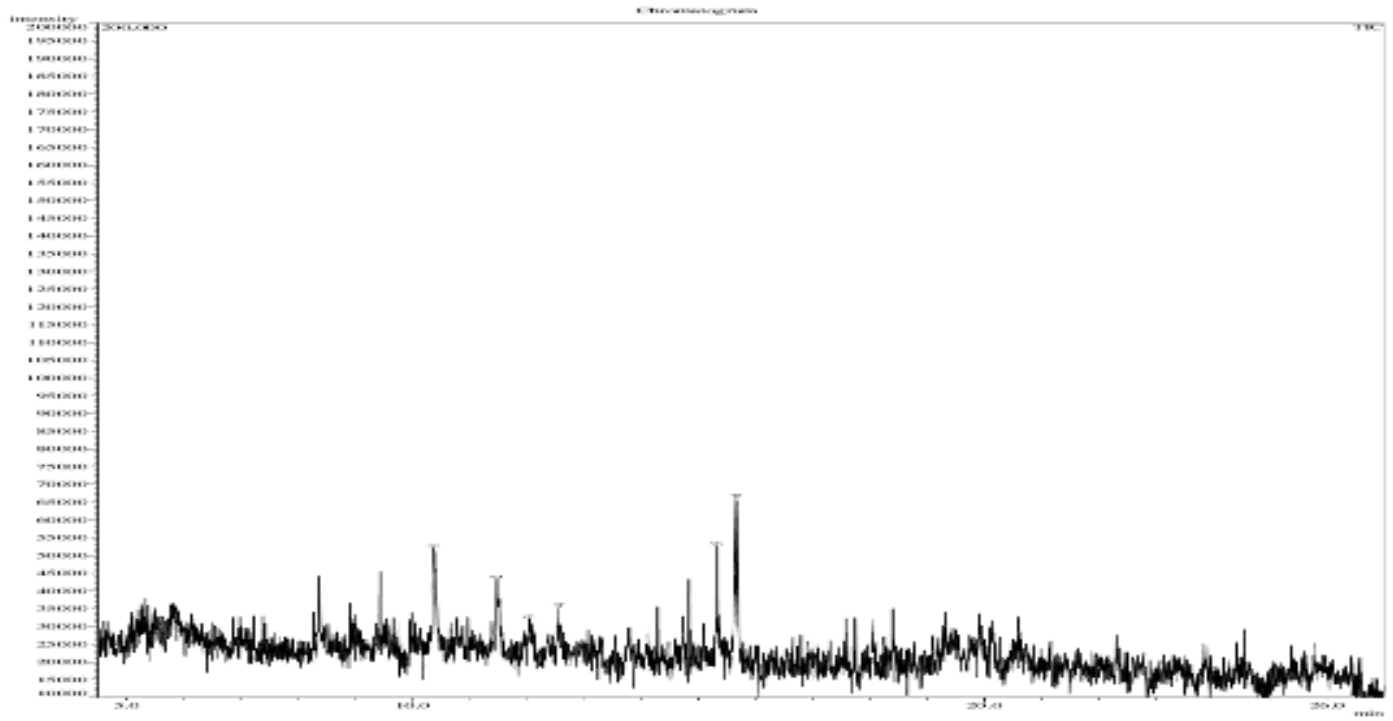


Fig.13 GC-MS chromatogram of Quercetin std.

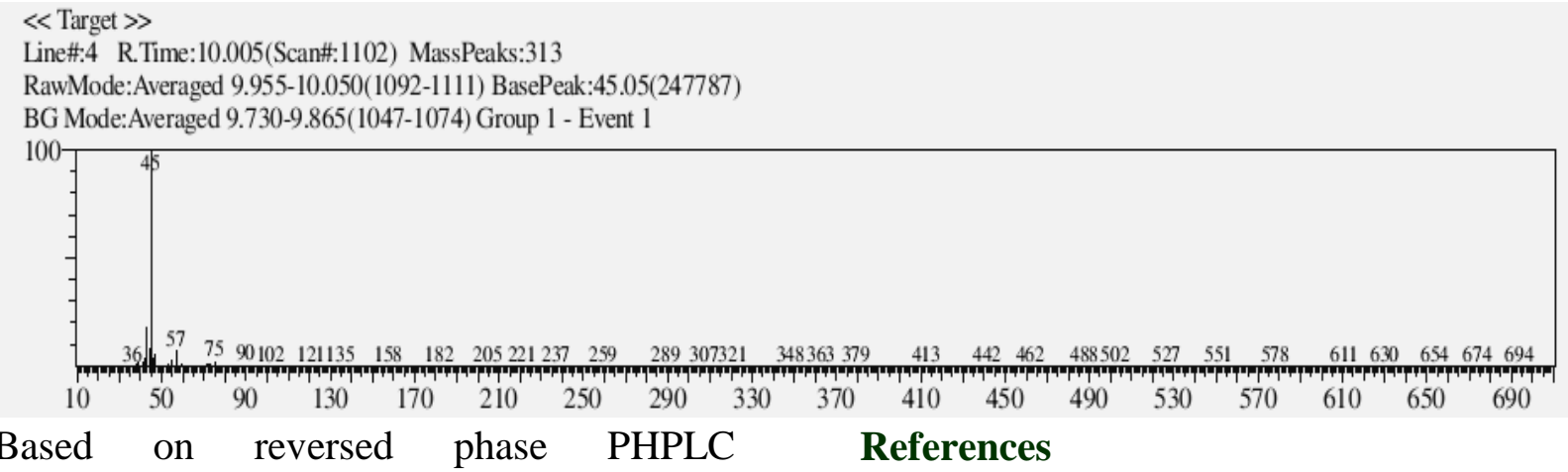

chromatograms for each fraction of Mango leaves extract together with most important phenol standards we confirmed that hot methanolic extract fraction contain high concentration of Quercetin, Rutin and Chlorogenic acid while ethanolic fraction contain high concentration of Quercetin and Caffeic acid, n-butanol fraction contain high concentration of Rutin and Quercetin, finally ethyl acetate fraction contain high concentration of Quercetin and chlorogenic acid. But the highest concentration of Quercetin found in ethyl acetate fraction of fresh leaves by using GC-MS.

In conclusion, the extensive survey of literature revealed that Mangifera indica is an important source of many pharmacologically and medicinally important chemicals. It is a potential source of polyphenolic compounds with high antioxidant activity that protect the body against damage linked to oxidative stress. The quantities of these compounds varies in different plant parts besides being affected by the geographic locations of the plants and method of extraction with suitable solvent. However, further researches are still required to elucidate the active ingredients and detail underlying mechanism that support its therapeutic use.

\section{Acknowledgments}

My great thanks to Dr. Enasjawad for her helps to bring Mango leaves.

Abdelnaser Abdelghany Elzaawely and Shinkichi Tawata. 2010. Preliminary Phytochemical Investigation on Mango Leaves. Word J. Agri. Sci., 6(6): 735-739.

Aiyegoro, O.A., Okoh, A.I. 2010. Preliminary pytochemical screening and in vitro antioxidant activities of the aqueous extract of Helichrysum longifolium DC. BMC Complement Altern. Med., 10: 21.

Augustin Scalbert, Gary Williamson. 2000. Dietary Intake and Bioavailability of Polyphenols. The American Society for Nutritional Sci., 130(8): 2073S-2085S.

Halilu, M.E., A. Abubakar, Garba, M. KandIsah, A.A. 2012. Antimicrobial and Preliminary Phytochemical studies of Methanol Extract of Root Bark of Crossopteryx febrifuga (Rubiaceae). $J$. Appl. Pharma. Sci., Vol. 2 (12), pp. 066-070.

Harborn, J.B. 1998. Phytochemical methods a guide to modern techniques of plant analysis.

Javier, E., Ramirez, Ricardo Zambrano, Beatriz Sepúlveda and Mario, J. 2014. Simirgiotis. Antioxidant Properties and Hyphenated HPLC-PDA-MS Profiling of Chilean PicaMango Fruits (Mangifera indica L. Cv. piqueño). Mol., 19: 438-458.

Joona, K., Sowmia, C., Dhanya, K.P., and Divya, M.J. 2013. Preliminary 
Phytochemical Investigation of Mangifera indica leaves and screening of Antioxidant and Anticancer activity.RJPBCS, 4(1): 1112- 1115.

Martin Masibo and Qian He. 2008. Major Mango Polyphenols and Their Potential Significance to Human Health. Comprehensive Rev. Food Sci. Food Safety, 7(4): 309-319.

Rajan, S., Thirunalasundari, T., Jeeva, S. 2011. Anti-enteric bacterial activity and phytochemical analysis of the seed kernel extract of Mangifera indica Linnaeus against Shigella dysenteriae (Shiga, corrig.) Castellani and Chalmers. Asian Pacific J. Trop. Med., 294-300.

Rajendra Prasad Bharti. 2013. Studies on
Antimicrobial Activity and Phytochemical Profile of Mangifera indica Leaf Extract. IOSR J. Environ. Sci. Toxicol. Food Technol., (IOSRJESTFT) 7(3): 74-78.

Syamsudin Abdillah, Risma Marisi Tambunan, Yunahara Farida, Ni Made DwiSandhiutami, Rita Marleta Dewi. 2015. Phytochemical screening and antimalarial activity of some plants traditionally used in Indonesia. Asian Pac. J. Trop. Dis., 5(6): 454-457.

Talba, A.M., M.M. Suleiman, M.A. Raji, S., J. Oniye. 2014. Phytochemical Screening and In-vitro Antibacterial Activity of Mangifera indica (Mango) Kernel on Aeromonascaviae. IOSR J. Pharm., 4(10): 45-50.

\section{How to cite this article:}

Dhuha Alshammaa. 2016. Preliminary Screening and Phytochemical Profile of Mangifera indica Leave's Extracts, Cultivated in Iraq. Int.J.Curr.Microbiol.App.Sci. 5(9): 163-173. doi: http://dx.doi.org/10.20546/ijcmas.2016.509.018 